\title{
PELATIHAN ANAK YATIM DAN DHUAFA DALAM UPAYA MENINGKATKAN PENGGUNAAN MICROSOFT WORD DAN MICROSOFT EXCEL DI ASRAMA DOMYADHU CABANG CIPUTAT
}

\author{
Dona Katarina ${ }^{1)}$, Ida Fitriani ${ }^{2)}$ \\ Informatika, Fakultas Teknik dan Ilmu Komputer, Universitas Indraprasta PGRI
}

\begin{abstract}
Abstrak
Seiring dengan perkembangan Teknologi Informasi, komputer dan penggunaanya dalam kehidupan sehari - hari, digunakan untuk mengolah data menjadi informasi. Salah satu program penting yang wajib dimiliki dan dikuasai oleh seorang pengguna komputer adalah Microsoft Office. Sesuai dengan namanya, program ini dapat membantu untuk mengerjakan pekerjaan mengolah data dengan lebih mudah. Di dalam Microsoft Office ada banyak jenis program yang bisa digunakan, misalnya Microsoft Word dan Microsoft Excel. Microsoft Word merupakan suatu program yang sangat penting dalam kehidupan sehari-hari. Program ini merupakan program pengolahan kata yang meliputi membuat, mengedit dan memformat dokumen. Sedangkan Microsoft Excel merupakan Program yang di desain untuk melakukan pengolahan angka. Tim pengabdian masyarakat Unindra akan melakukan kegiatan pengabdian masyarakat di Yayasan Domyadhu di cabang Ciputat yaitu dengan memberikan pelatihan tentang penggunaan Microsoft Word dan Microsoft Excel. Dengan melakukan pelatihan ini diharapkan dapat meningkatkan keilmuan tentang penggunaan Microsofot Word dan Microsoft Excel pada adik - adik di Yayasan.
\end{abstract}

Kata Kunci : Microsoft Word, Microsoft Excel, Yayasan, Domyadhu

\begin{abstract}
Along with the development of Information Technology, computers and their use in everyday life are used to process data into information. One of the important programs that a computer user must have and control is Microsoft Office. As the name implies, this program can help to do data processing work more easily. In Microsoft Office there are many types of programs that can be used, for example Microsoft Word and Microsoft Excel. Microsoft Word is a program that is very important in everyday life. This program is a word processing program that includes creating, editing and formatting documents. Meanwhile, Microsoft Excel is a program designed to perform number processing. The Unindra community service team will carry out community service activities at the Domyadhu Foundation in the Ciputat branch by providing training on the use of Microsoft Word and Microsoft Excel. By conducting this training, it is hoped that it can improve knowledge on the use of Microsofot Word and Microsoft Excel for younger siblings at the Foundation.
\end{abstract}

Keywords: Microsoft Word, Microsoft Excel, Foundation, Domyadhu

Correspondence author: Dona Katarina, dona.katrin@gmail.com, Jakarta, Indonesia 


\section{PENDAHULUAN}

Komputer merupakan teknologi yang terus berkembang dan sangat membantu dalam kehidupan. Ada banyak program yang ada disana yang membantu kita agar dapat mengerjakan pekerjaan lebih cepat dan tepat. Salah satu program penting yang wajib dimiliki dan dikuasai oleh seorang pengguna komputer adalah Microsoft Office. Sesuai dengan namanya, program ini dapat membantu untuk mengerjakan pekerjaan mengolah data dengan lebih mudah. Di dalam Microsoft Office ada banyak jenis program yang bisa digunakan, misalnya Microsoft Word dan Microsoft Excel.

Microsoft Word merupakan suatu program yang sangat penting dalam kehidupan sehari-hari. Program ini merupakan program pengolahan kata yang meliputi membuat, mengedit dan memformat dokumen. Sedangkan Microsoft Excel merupakan Program yang didesain untuk melakukan pengolahan angka. Microsoft Excel dilengkapi dengan berbagai macam fungsi untuk kalkulasi. Dengan menggunakan program ini, maka kita bisa melakukan perhitungan data dalam wujud angka dengan lebih mudah.

Domyadhu (dompet yatim dhu'afa) adalah lembaga amil zakat yang berfokus pada pendidikan dan pendayagunaan yatim dan dhu'afa. Rata - rata adik - adik di yayasan Domyadhu cabang Ciputat bersekolah di tempat yang tidak jauh dari yayasan. Karena tidak semua adik - adik mendapatkan pelajaran tentang komputer dan kurangnya ketersediaan komputer di yayasan membuat adik - adik belum mengetahui cara menggunakan Microsoft Word dan Microsoft Excel. Maka dari itu, Tim Unindra akan melakukan kegiatan Pengabdian Masyarakat di Domyadhu cabang Ciputat dengan harapan dapat menambah pengetahuan adik - adik tentang penggunaan Microsoft Word dan Microsoft Excel.

\section{METODE PELAKSANAAN}

Kegiatan Pengabdian Masyarakat di Yayasan Domyadhu dilaksanakan selama 4 bulan yaitu dari bulan September 2019 - Desember 2019 yang beralamat di Jl. Aria Putra Raya No. 14 Rt 003/002 Serua, Ciputat-Tangerang Selatan, Provinsi Banten.

Dalam kegiatan pelatihan ini, tim Pengabdian Masyarakat Unindra menggunakan modul materi untuk memberikan penjelasan mengenai cara menggunakan Microsoft Word dan Microsoft Excel. Prosedur yang dilakukan oleh tim Pengabdian Masyarakat Unindra di Yayasan Domyadhu antara lain :

1. Survey ke lokasi mitra dan menjelaskan tujuan dari pengabdian masyarakat.

2. Mengkomunikasikan desain pelatihan Microsoft Word dan Microsoft Excel ke pihak mitra.

3. Mengembangkan materi yang akan disampaikan saat pelatihan Microsoft Word dan Microsoft Excel

4. Pelaksanaan pengabdian masyarakat di Yayasan Domyadhu

5. Analisa hasil kegiatan pengabdian masyarakat di Yayasan Domyadhu

\section{HASIL DAN PEMBAHASAN}

Kegiatan pengabdian masyarakat dengan judul "PKM pada anak yatim dan dhuafa dalam meningkatkan penggunaan Microsoft Word dan Microsoft Excel di Asrama Domyadhu cabang Ciputat" berjalan dengan baik. Untuk menunjang pelaksanaan kegiatan pelatihan ini Kami sebagai Tim telah mempersiapkan semua peralatan yang dibutuhkan seperti laptop dan proyektor sebagai media yang penting dalam kegiatan abdimas, lalu membuat banner serta mempersiapkan semua ATK yang dibutuhkan saat kegiatan. Untuk kegiatan pelatihan Microsoft Word, Kami selaku Tim abdimas 
memberikan penjelasan kepada Adik-adik di Yayasan Domyadhu mengenai button button yang ada di Microsoft Word beserta fungsinya dan sebagai contoh mempraktekan langsung membuat jadwal pelajaran di sekolahnya masing - masing dengan memanfaatkan button Shapes dan WorArt yang ada pada menu Insert di Microsoft Word. Sedangkan saat pelatihan Microsoft Excel, adik - adik diberi penjelasan mengenai manfaat dari penggunaan Microsoft Excel dan mempraktekkannya langsung penggunaan fungsi MAX, MIN dan SUM (penjumlahan) pada Microsoft Excel.

Dari pemaparan realisasi kegiatan pada pembahasan diatas, adapun hasil yang diperoleh dari kegiatan ini yaitu adik - adik di Yayasan domyadhu mendapat pengetahuan tentang penggunaan Microsoft Word dan Microsoft Excel sehingga diharapkan dapat dipraktekan secara langsung saat kegiatan pengabdian masyarakat. Berikut beberapa foto kegiatan Kami pada Saat pelatihan di Yayasan Domyadhu Anak Yatim dan Kaum Dhuafa.

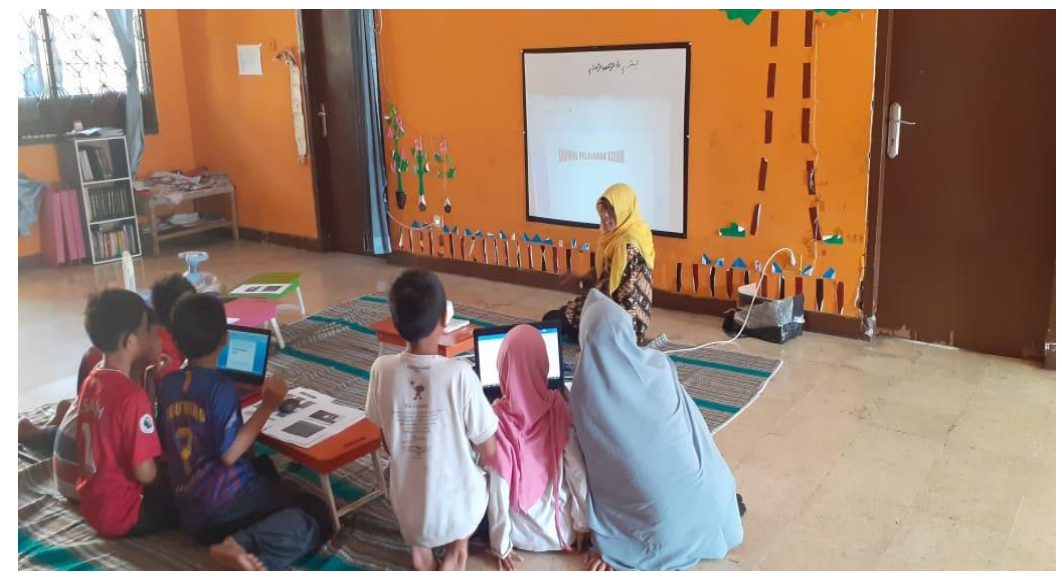

Gambar 1. Tim Dosen Sedang Memberikan Materi Microsoft Word

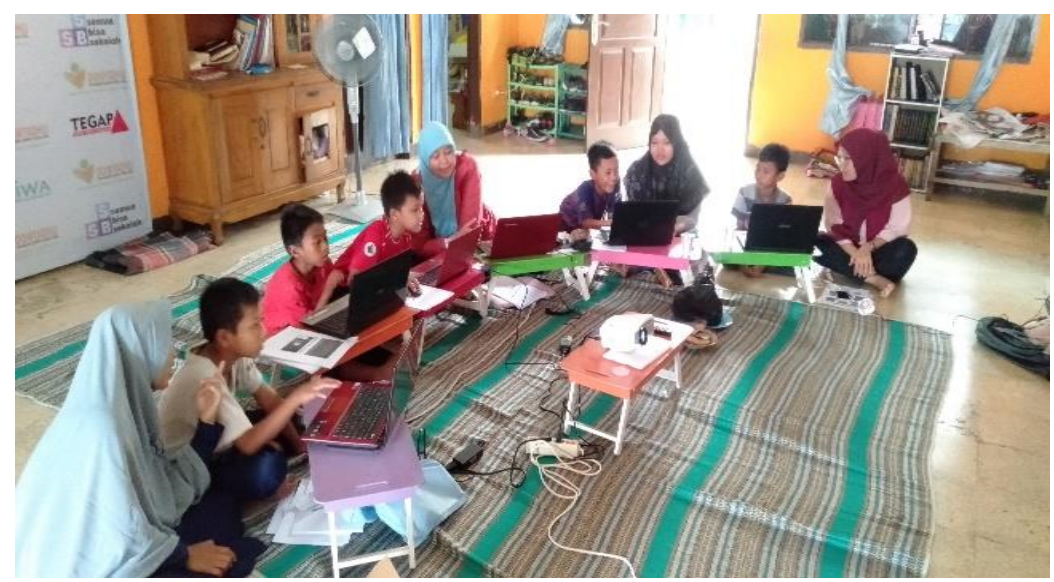

Gambar 2. Tim Dosen Sedang Memberikan Materi Microsoft Word 


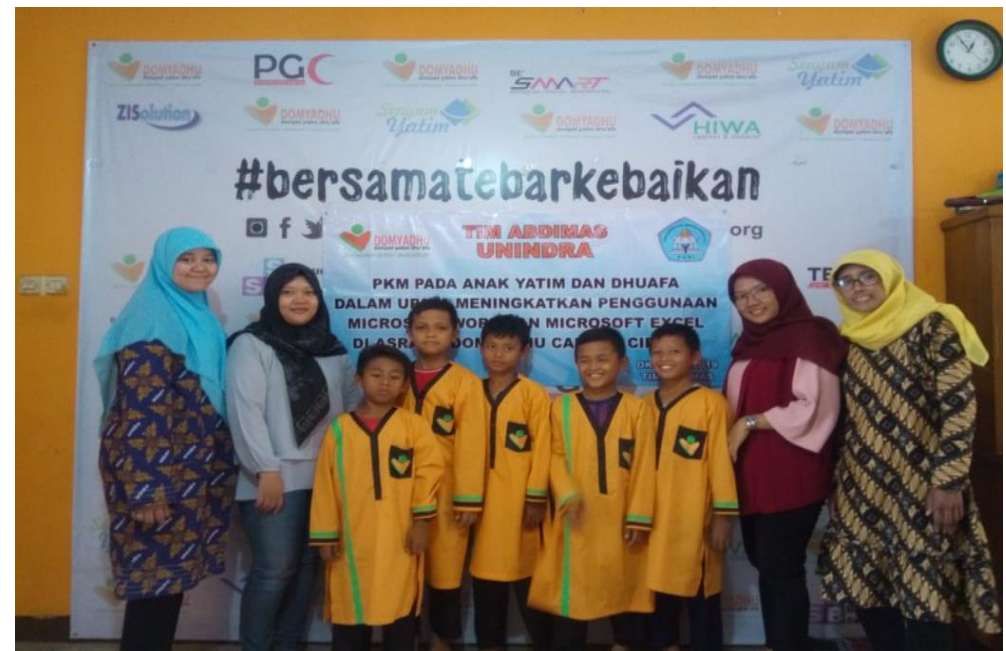

Gambar 3. Tim Dosen Melaksanakan Foto Bersama dengan Adik-adik di Dpmyadhu

\section{SIMPULAN}

Kegiatan Pengabdian Masyarakat yang dilakukan di Yayasan Domyadhu cabang Ciputat berjalan dengan baik. Adik-adik memperhatikan materi yang disampaikan dengan baik. Dengan diadakannya kegiatan pengabdian masyarakat ini diharapkan adik - adik sudah mengetahui tentang penggunaan Microsoft Word dan Microsoft Excel serta dapat diterapkan dalam kegiatan di Sekolah.

\section{DAFTAR PUSTAKA}

http://domyadhu.org/banten/

https://salamadian.com/pengertianmicrosoft-word-excel-access/

http://dsitd.ipb.ac.id/wpcontent/uploads/2017/10/Modul-PelatihanMicrosoft-Word2013.pdf

http://dsitd.ipb.ac.id/wpcontent/uploads/2017/10/Modul-PelatihanMicrosoft-Excel2013-1.pdf 